\title{
Identifikasi Bahaya dan Risiko Keselamatan Kerja Pada Saat Overhaul di Area Kiln PT. X tahun 2017
}

\author{
Surika Martalina ${ }^{1}$, Husna Yetti $^{2}$, Yuniar Lestari $^{2}$
}

\begin{abstract}
Abstrak
Overhaul merupakan perbaikan mesin atau alat secara total yang dilakukan oleh perusahaan supaya kinerja mesin atau alat bekerja dengan baik. Perusahaan membutuhkan tenaga kerja yang banyak dengan waktu yang telah di tentukan serta tekanan kerja yang tinggi berisiko terjadinya kecelakaan kerja pada saat overhaul. Pengurangan terjadinya kecelakaan kerja maka dibutuhkan penelitian tentang Identifikasi bahaya dan risiko keselamatan kerja pada saat overhaul di area kiln PT X. Tujuan penelitian ini adalah mengidentifikasi bahaya dan risiko keselamtaan kerja pada saat overhaul di area kiln PT X. Studi ini merupakan penelitian kualitatif dengan metode triangulasi dan semi kuantitatif berdasarkan Australian Standard/New Zealand Standard (AS/NZS) 4360:2004. Hasil penelitian mendapatkan 91 bahaya dan 126 risiko yang teridentifikasi dan sebagian besar dari kegiatan di area kiln adalah pemasangan scaffolding, pengelasan dan bongkar pasang alat yang rusak. Perusahaan ini perlu melakukan training Keselamatan dan Kesehatan Kerja (K3) kepada pekerja serta menumbuhkan budaya peduli antara pekerja agar tindakan unsafe action tidak terjadi.
\end{abstract}

Kata kunci: identifikasi bahaya dan risiko, keselamatan Kerja, overhaul, AS/NZS 4360:2004

\section{Abstract}

Overhaul is a total machine or tool repair performed by the company so that machine or tool performance works well. Companies need a lot of workforce with a set time and high working pressure at risk of work accidents during overhaul. To reduce the occurrence of occupational accidents, it is necessary research on the identification of hazards and occupational safety risks during the overhaul in the kiln area of PT. $X$. The objective of this study was to identify the dangers and risks of work safety during the overhaul in the kiln area of PT. $X$. This was a qualitative research with semiquantitative and triangulation method based on Australian Standard / New Zealand Standard (AS / NZS) 4360: 2004. The results showed 91 hazards and 126 identified risks and most of the activities in the kiln area were the installation of scaffolding, welding and disassembling tools. This companies need to conduct training occupational health and safety to workers and foster care culture between workers to action unsafe action does not happen. Keywords: hazards and risk identification, safety, overhaul, AS/NZS 4360: 2004

Affiliasi penulis: 1. Prodi S2 Kesehatan Masyarakat Fakultas Kedokteran Universitas Andalas. 2. Bagian IImu Kesehatan Masyarakat Fakultas Kedokteran Universitas Andalas.

Korespondensi: Surika Martalina, Email: surika.martalina@gmail.com HP. 08116613357

\section{PENDAHULUAN}

Keselamatan dan Kesehatan Kerja

merupakan suatu usaha untuk menciptakan perlindungan dan keamanan dari berbagai risiko kecelakaan dan bahaya, baik fisik, mental maupun emosional terhadap pekerja, perusahaan, masyarakat dan lingkungan. ${ }^{1}$ Berdasarkan data International Labour Organization (ILO) tahun 2013, satu pekerja di dunia meninggal setiap 15 detik karena kecelakaan kerja atau penyakit akibat kerja. Diperkirakan 2,3 juta pekerja meninggal setiap tahun akibat kecelakaan dan Penyakit Akibat Kerja (PAK). Lebih dari 160 juta pekerja menderita penyakit akibat kerja dan 313 juta pekerja mengalami kecelakaan non-fatal per tahunnya. ${ }^{2} \mathrm{Di}$ Indonesia jumlah kecelakaan kerja tahun 2014 sebanyak 24.910 kasus dan tahun 2015 sebanyak 105.182 kasus, sehingga jumlah kecelakaan kerja dari tahun ke tahun 
mengalami tren peningkatan, diperkirakan kenaikan angka kecelakaan kerja sebesar $5 \%-10 \%$ setiap tahunnya. ${ }^{3}$

PT. X merupakan perusahaan yang bergerak dibidang persemenan, untuk meningkatkan produksi semen, Perusahaan berusaha untuk menjaga produktivitas pabrik-pabrik yang ada di PT. X. Hal tersebut dilakukan dengan cara memperbaiki mesin produksinya (overhaul) setiap tahun atau berkala dengan cara penggantian spare part (refurbish), penggantian mesin (replace), maupun upgrade kapasitas. Perusahaan akan mengeluarkan banyak cost (biaya) hanya untuk overhaul mesin produksi, karena mesin tersebut memiliki lifetime (umur pakai) sehingga harus ada perawatan maupun perbaikannya. Salah satu perawatan yang dilakukan adalah dengan cara overhaul.

Berdasarkan survei pendahuluan dan wawancara yang telah dilakukan di PT. X, diperoleh informasi bahwa Identifikasi bahaya dan risiko keselamatan kerja di PT. $X$ belum diterapkan pada saat pelaksanaan overhaul. Data kecelakaan kerja tiga tahun terakhir di PT. X tahun 2014 terjadi 12 kasus kecelakaan kerja, tahun 2015 terjadi 14 kasus kecelakaan kerja dan tahun 2016 terjadi 15 kasus kecelakaan kerja. Dari data tersebut dapat disimpulkan meningkatnya jumlah kasus kecelakaan kerja tiap tahunnya.

Perencanaan dan kontrol kegiatan overhaul ini merupakan tugas dari departeman teknik pabrik dengan melakukan penilaian menggunakan metode MPI (Maintenance Priority Index) dalam menentukan prioritas utama dalam pengerjaan overhaul. Hasil penilaian tersebut didapatkan bahwa area kiln yang menjadi prioritas utama dalam melakukan pekerjaan overhaul. Berdasarkan uraian diatas, perlu diteliti tentang "Identifikasi Bahaya dan Risiko Keselamatan Kerja Pada Saat Overhaul di Area Kiln PT. X Tahun 2017".

\section{METODE}

Penelitian ini merupakan studi kualitatif dan semi kuantitatif dengan metode triangulasi dimana penelitian kualitatif dengan metode triangulasi digunakan dalam melakukan identifikasi risiko untuk mengetahui potensi risiko pada setiap proses kegiatan overhaul di area kiln kemudian melakukan analisis, nilai, tingkatan risiko menggunakan metode analisis data risiko semi kuantitatif berdasarkan Australian Standard/New Zealand Standard (AS/NZS) 4360: 2004. ${ }^{4}$ Penelitian ini dilakukan pada saat overhaul di area kiln PT. X pada bulan Mei sampai Juni 2017. Jumlah informan pada penelitian kualititatif 3 orang dan untuk penelitian semi kuantitatif berjumlah 42 orang.

\section{HASIL}

\section{Pemasangan scafolding}

Pada kegiatan ini pekerja melakukan penyusunan pipa-pipa besi hingga membentuk tangga untuk bekerja pada ketinggian. Bahaya yang akan muncul diantaranya adalah bahaya bekerja di ketinggian dan bahaya ergonomi. Risiko yang muncul dari bahaya tersebut yaitu terjatuh dari ketinggian,terpeleset saat memasang pipa, terbentur, terpukul, tertimpa benda.

\section{Mengganti lifter didalam cooler}

Pekerja membuka lifter dengan menggunakan mesin las dan memasang lifter baru dengan melakukan penguncian baut. Bahaya yang timbul dari pekerjaan ini diantaranya bahaya bekerja di ruang terbatas, bahaya kondisi udara dengan kelembaban rendah, bahaya ergonomi, bahaya listrik, bahaya radiasi karena proses pengelasan, bahaya terkena mesin yang panas dan risiko yang timbul diantaranya terpapar panas benda kerja, tersentrum, terbentur, terpukul, terpapar asap las, terpapar cahaya las, terjepit, kebakaran, tertimpa, terpapar debu.

\section{Mengganti cooler}

Membuka cooler set dengan mesin las kemudian diturunkan dengan alat angkat (crane) setelah itu dinaikkan cooler set yang baru dengan crane dan dilakukan pengelasan untuk penyambungan. Bahaya yang muncul bahaya bekerja di ketinggian, bahaya kejatuhan benda asing, bahaya terkena bagian mesin yang bergerak, bahaya ergonomi, bahaya listrik, bahaya radiasi karena proses pengelasan, bahaya terkena mesin yang panas. Risiko yang timbul diantaranya terjatuh, terpapar panas, tersentrum, terpeleset, terbentur, terpukul, terpapar asap las, terpapar cahaya las, terjepit, kebakaran, tertimpa benda. 


\section{Membongkar batu tahan api}

Penghancuran batu yang menempel pada dinding kiln dengan alat bor kemudian pecahan batu dibuang dengan alat berat (skid steer loader). Bahaya yang timbul diantaranya bahaya bekerja di ketinggian, bahaya kejatuhan benda asing, bahaya mesin yang bergerak, bahaya diruang terbatas, bahaya kondisi kelembaban yang rendah, bahaya kebisingan, bahaya ergonomi, bahaya listrik, bahaya radiasi karena proses pengelasan, bahaya terkena mesin yang panas. Risiko yang dapat muncul diantaranya terpeleset, terbentur, terpapar getaran mesin, tertimpa, tertabrak, terpapar debu.

\section{Memasang batu tahan api}

Menyusun batu tahan api yang baru pada dinding kiln menggunakan alat berat (mall toring dan fork lift). Bahaya yang timbul ialah bekerja di ketinggian, bahaya kejatuhan benda asing, bahaya terkena bagian mesin yang bergerak, bahaya bekerja diruang terbatas, bahaya kondisi udara dengan kelembaban yang rendah, bahaya kebisingan, bahaya ergonomi. Risiko yang dapat terjadi diantaranya terjatuh, terpeleset, terbentur, terpukul, terjepit, tertimpa, tertabrak, terpapar debu.

\section{Mengganti chain bridge scrapper}

Kegiatannya adalah membuka rantai transfer material dengan cara membuka sambungannya dengan palu besi dan mesin las. Kemudian memasang rantai yang baru dengan menyambungkan pinnya. Bahaya terkena bagian mesin yang bergerak, bahaya ergonomi, bahaya listrik, bahaya radiasi karena proses pengelasan. Risiko yang timbul terpapar panas, tersayat, tersentrum, terpeleset, terbentur, terpukul, terpapar asap las, terpapar cahaya las, terjepit, kebakaran, tertimpa, terpotong.

\section{Menggerinda supporting roller}

Melakukan penggerindaan (amplas) pada permukaan supporting roller (roda penyangga kiln) agar rata. Bahaya terkena bagian mesin yang bergerak, bahaya ergonomi, bahaya listrik. Risiko ialah terpotong, terjepit, terpapar getaran, tersayat, sentrum, terpeleset.

\section{Membuka impeller 2J1P01}

Membuka blade pada hub impeller dengan cara membuka bautnya (menggunakan kunci atau mesin las) dan menggantung blade tersebut dengan alat angkat (katrol) kemudian dipindahkan ke tempat yang aman. Bahaya yang timbul ialah bekerja di ketinggian, bahaya kejatuhan benda asing, bahaya terkena bagian mesin yang bergerak, bahaya bekerja diruang terbatas, bahaya kondisi udara dengan kelembaban yang rendah, bahaya ergonomi, bahaya radiasi karena proses pengelasan, bahaya terkena mesin yang panas. Risikonya terjatuh, tersayat, tersentrum, terpeleset, terbentur, terpukul, terpapar asap las, terpapar cahaya las, terjepit, kebakaran, tertimpa, terpapar debu.

\section{Memasang impeller 2J1P01}

Mengangkat blade yang baru dengan katrol kemudian diposisikan pada hub impeller dan memasang baut pengikatnya. Bahaya yang timbul ialah bekerja di ketinggian, bahaya kejatuhan benda asing, bahaya terkena bagian mesin yang bergerak, bahaya bekerja diruang terbatas, bahaya kondisi udara dengan kelembaban yang rendah, bahaya ergonomi. Risiko : terjatuh, tersayat, terpeleset, terbentur, terpukul, terjepit, tertimpa, terpapar debu.

\section{Mengganti damper fan 2J1P02}

Membuka katup pada pipa udara buang fan dengan cara membuka baut sambungannya menggunakan kunci atau mesin las kemudian mengangkatnya dengan katrol. Setelah itu angkat katup (damper) yang baru dan posisikan pada pipa udara buang kemudian lakukan penguncian bautnya dan pengelasan pada beberapa sisi. Bahayanya ialah bekerja di ketinggian, bahaya kejatuhan benda asing, bahaya terkena bagian mesin yang bergerak, bahaya bekerja diruang terbatas, bahaya kondisi udara dengan kelembaban yang rendah, bahaya ergonomi, bahaya listrik, bahaya radiasi karena proses pengelasan, bahaya terkena mesin yang panas, terjatuh, terpapar panas, tersayat, tersentrum, terpeleset, terbentur, terpukul, terpapar asap las, terpapar cahaya las, terjepit, kebakaran, tertimpa. 


\section{Pengelasan hausing fan 2J1P02}

Menambal rumah impeller yang bocor dengan cara melakukan pengelasan besi plat pada bagian yang bocor. Bahaya yang timbul antara lain bahaya bekerja di ketinggian, bahaya kejatuhan benda asing, bahaya terkena bagian mesin yang bergerak, bahaya bekerja diruang terbatas, bahaya kondisi udara dengan kelembaban yang rendah, bahaya ergonomi, bahaya listrik, bahaya radiasi karena proses pengelasan, bahaya terkena mesin yang panas. Risiko yang ada ialah terjatuh, terpapar panas, tersayat, tersentrum, terpeleset, terbentur, terpukul, terpapar asap las, terpapar cahaya las, kebakaran.

\section{Modifikasi screw}

Membuka screw yang lama dengan cara membuka bautnya dengan kunci atau mesin las kemudian diangkat dengan katrol setelah itu melakukan modifikasi pada ducting (pipa keluar) dengan menggunakan mesin las, kemudian angkat screw yang baru dengan katrol dan pasangkan pada kedudukannnya dengan penguncian baut-bautnya. Bahayanya ialah bekerja di ketinggian, bahaya kejatuhan benda asing, bahaya terkena bagian mesin yang bergerak, bahaya ergonomi, bahaya listrik, bahaya radiasi karena proses pengelasan, bahaya terkena mesin yang panas. Risiko yang mungkin ialah terjatuh, terpapar panas, tersentrum, terpeleset, terbentur, terpukul, terpapar asap las, terpapar cahaya las, terjepit, kebakaran, tertimpa.

\section{Mengganti canvas air sluice}

Membuka casing (rumah) alat transport material (air sluice) dengan cara membuka bautnya dengan kunci, kemudian lakukan penggantian kain kanvas (filter pembatas antara udara dan material) yang berada di bagian dalamnya. Setelah itu pasang kembali casingnya dengan melakukan pengunciat bautnya. Bahaya bekerja diruang terbatas, bahaya kondisi udara dengan kelembaban yang rendah, bahaya kejatuhan benda asing. Risiko yang ada ialah terpeleset, terbentur, terpukul, terjepit, terpapar debu.

\section{Mengganti bearing metal}

Membuka bearing metal yang menjadi tumpuan mill dengan cara mengangkat mill tersebut dengan hydraulic jack dan menarik bearing metal yang berada dibawahnya dengan katrol. Setalah itu masukkan bearing metal yang baru dengan katrol. Bahaya bekerja di ketinggian, bahaya kejatuhan benda asing, bahaya terkena bagian mesin yang bergerak, bahaya bekerja diruang terbatas, bahaya kondisi udara dengan kelembaban yang rendah, bahaya ergonomi, bahaya listrik, bahaya radiasi karena proses pengelasan, bahaya terkena mesin yang panas. Risiko yang mungkin ialah terjatuh, tersayat, terpeleset, terbentur, terpukul, terjepit, tertimpa, terpotong

\section{PEMBAHASAN}

Hasil observasi dan wawancara mendalam dengan informan pada penelitian ini diperoleh informasi bahwa terdapat empat belas kegiatan utama di area kiln PT. X. Sebagian besar dari kegiatan tersebut adalah pemasangan scaffolding, pengelasan dan bongkar pasang alat yang rusak. Kegiatan ini dapat menimbulkan beberapa potensi bahaya dan risiko dalam pengerjaannya.

Bahaya dan risiko saat melakukan pemasangan scaffolding pada penelitian ini, ditemukan bahayabahaya ditempat kerja seperti bahaya di ketinggian dan bahaya ergonomi serta risiko yang dapat muncul dari bahaya tersebut adalah terjatuh dari ketinggian, terpeleset saat memasang pipa, terbentur, terpukul, dan tertimpa. Hal ini sejalan dengan penelitian Soputan (2014), bahwa pada saat bongkar pasang scaffolding, bahaya yang ditemukan adalah bahaya berkerja diketinggian dan risiko yang dapat terjadi yaitu pekerja jatuh dari ketinggian, tertimpa, dan terluka saat bekerja. ${ }^{5}$ Begitu juga dengan penelitian yang dilakukan oleh Persada (2015), yaitu identifikasi bahaya saat pemasangan scaffolding antara lain bahaya bekerja di ketinggian dan ergonomi serta risiko yang muncul yaitu tangan terjepit, tertimpa material, kepala terbentur, kaki tersandung, dan terpeleset. ${ }^{6}$ Beberapa penelitian tentang scaffolding mempunyai potensi bahaya dan risiko yang hampir sama dengan yang dilakukan oleh peneliti.

Upaya yang dilakukan untuk mencegah terjadinya kecelakaan kerja saat pemasangan scaffolding antara lain lantai di beri papan yang kuat dan rapat sehingga dapat menahan bobot pekerja selama melakukan pemasangan. Pemberian pagar pengaman 
apabila tingginya lebih dari 2 meter. Menurut Peraturan Menakertrans No. 1 Per/Men/1980 tentang keselamatan dan kesehatan kerja pada konstruksi bangunan serta didukung dengan dokumen perusahaan No. DT/PSM10/05 tanggal 22 Desember tahun 2008 bahwa dengan semakin meningkatnya pembangunan dengan penggunaan teknologi modern, harus diimbangi pula dengan upaya keselamatan tenaga kerja atau orang lain yang berada di tempat kerja. ${ }^{7}$

Pekerjaan pengelasan pada penelitian ini ditemukan beberapa bahaya dan risiko antara lain bahaya listrik, bahaya radiasi karena proses pengelasan, dan bahaya terkena mesin yang bergerak. Risiko yang dapat ditimbulkan dari bahaya tersebut yaitu tersentrum, terpapar asap las, terpapar cahaya las, kebakaran, terpapar debu dan terpapar panas. Penelitian Jokosisworo (2007) juga menemukan bahwa saat melakukan pengelasan pekerja berada pada bahaya listrik dan bahaya kejatuhan benda kerja sehingga berisiko terkena kecelakaan kerja seperti: terkena aliran listrik, jatuh, radiasi, mata terkena sinar ultra violet, dan partikel/debu di udara, asap dan gas serta kejatuhan benda-benda. ${ }^{8}$ Keselamatan kerja seorang pengelas tidak boleh dipandang ringan. Pengelas dan pekerja lain yang bekerja ditempat pemotongan dan pengelasan harus memperhatikan semua faktor keselamatan, seperti penggunaan kaca las, topi kerja atau helm, pakaian kerja, sarung tangan kulit dan peralatan lainnya yang dibutuhkan.

Pada penelitian ini juga teridentifikasi bahaya dan risiko saat melakukan bongkar pasang alat yang rusak yaitu bahaya kejatuhan benda asing, ergonomi, kebisingan, bekerja diruang terbatas, dan terkena mesin yang bergerak. Sedangkan risiko yang timbul dari bahaya tersebut adalah tertimpa, terjepit, terpotong, tersayat, terbentur. Hal ini sejalan dengan penelitian Bangun dan Nawawinetu (2014) bahwa bahaya saat perbaikan mesin di unit packaging di PT. X seperti bahaya tertimpa, bahaya terjepit, ${ }^{9}$ bahaya terkena percikan api material, bahaya roda gerinda. Risiko yang ditimbulkan yaitu terjepit, tertimpa, terpapar cahaya las, terpotong. Keselamatan saat bongkar pasang alat perlu diperhatikan, seperti kerja sesuai dengan IK (Instruksi Kerja), setelah itu menggunakan peralatan kerja yang tepat sesuai dengan peruntukannya, jika membongkar komponen hidrolik, pastikan tidak ada tekanan yang bekerja, selanjutnya gunakan prosedur LOTO (Lock Out Tag Out) untuk mencegah operator atau rekan kerja mengoperasikan alat yang sedang kita perbaiki. Hindari bekerja ketika mesin sedang beroperasi.

\section{SIMPULAN}

Terdapat 91 bahaya dan 126 risiko kerja yang teridentifikasi pada saat overhaul di area kiln PT. X. Sebagian besar dari kegiatan di area kiln adalah pemasangan scaffolding, pengelasan dan bongkar pasang alat yang rusak.

\section{DAFTAR PUSTAKA}

1. Suma'mur. Higiene perusahaan dan kecelakaan kerja. Jakarta: Sagung Seto; 2013.

2. International Labour Organization (ILO). Keselamatan dan kesehatan kerja. Indonesia: Score; 2013.

3. BPJS Ketenagakerjaan. Jumlah kecelakaan kerja di indonesia masih tinggi. 2016 (diunduh 11 Januari 2017). Tersedia dari

http://www.bpjsketenagakerjaan.go.id.

4. AS/NZS 4360. 3rd Edition the australian and new zealand standard on risk. NSW Australia: Broadleaf Capital International; 2004.

5. Soputan GEM. Manajemen risiko keselamatan dan kesehatan kerja (K3) (study kasus pada pembangunan gedung SMA Eben Haezar). Jurnal IImiah Media Engneering. 2014;4(4): 229-38.

6. Persada YB. Risk assesment K3 pada proses pengoperasian scaffolding pada proyek apartemen PT. X di Surabaya. Journal of occupational safety and health. 2015;4:199-210.

7. Menteri Tenaga Kerja dan Transmigrasi Republik Indonesia. Peraturan menteri tenaga kerja dan transmigrasi No. PER.01/MEN/1980 tentang keselamatan dan kesehatan kerja pada konstruksi bangunan. 1980 (diunduh 10 Juni 2017). Tersedia dari http://www.pnk3.com/files/perpu/58847.

8. Jokosisworo S. Keselamatan pengelasan. Jurnal teknik perkapalan. 2007;4(1) :11-4.

9. Bangun YP, Nawawinetu. ED. Risk Assesment pada pekerja maintanance di PT $X$. Journal of Occupational Safety and Health. 2014;3(2):170-81. 